\title{
Rays and Skates of Devon and Cornwall. Methods of Rapid Identification on the Fishmarket.
}

$\mathrm{By}$

\author{
G. A. Steven, B.Sc., F.R.S.E., \\ Assistant Naturalist at the Plymouth Laboratory.
}

With 10 Figures in the Text.

IN carrying out detailed investigations into the life-histories and distribution of the Rays and Skates around the extreme south-west of England, large numbers of commercial landings have had to be examined. On account of their size and cost, regular and adequate samples of Rays and Skates cannot be delivered at the laboratory, as is possible with such a small and inexpensive fish as the Herring, for example. It therefore has been essential to learn rapidly to distinguish the different species as they lie exposed for sale on the fishmarkets. This has been necessary not only to promote rapidity of work, but also to obviate all unnecessary handling of the fish, too much interference with which is apt greatly to annoy fishermen, salesmen, and buyers alike.

As Rays and Skates are laid out for sale in lots often of one hundred or more all with their lower surfaces upwards, the task of identifying the species without raising each fish to examine its upper side was found at first to be one of extreme difficulty, and accurate determinations were not possible. But gradually, as the result of concentration and much practice, it became possible to identify-simply from the characters discernible on their under surfaces - the eleven species of Raia landed at the various ports of Devon and Cornwall. Only when this facility has been acquired is it possible to make a general survey of the stocks present on the various fishing grounds by dealing rapidly, amidst the bustle and confusion of a busy market, with large numbers of fish in commercial catches.

In this paper, therefore, an attempt is made to enumerate and describe as clearly as possible the distinguishing features which have been found most useful for rapid identification of the species landed in this area. The descriptions are applicable to fishes of marketable size, and must not be expected to apply to stages less than about $30 \mathrm{~cm}$. across the disc 
which do not ordinarily find a place in commercial landings. It will readily be understood, too, that minute details of obscure features, no. matter how diagnostic they may be, will receive no mention.*

By careful observation of the characters here described any worker, even without previous experience of the family, should be able to distinguish with certainty and ease at least seven of the eleven species of Raia. likely to be seen on the fishmarkets of Devon and Cornwall. The four others are less easily recognised, but a little patient practice should render possible the identification of them also from the characters normally visible on the under side. Nevertheless, even the experienced worker will encounter, from time to time, a fish which will require at least a glance at the upper surface to establish its identity. Occasionally, too, a specimen may occur which will be at once recognisable as either Raia brachyura or R. montagui - two short-nosed Rays often very similar in appearancebut cannot readily be assigned to its correct species even on careful examination of both sides. In such circumstances the easiest and most. certain method of deciding the point, if several other undoubted examples of both species be available, is as follows :-

Lay out, back upwards, two separate lots of fish, one lot consisting of $R$. brachyura alone and the other of $R$. montagui alone. This done, place the doubtful specimen in the middle first of the one lot and then of the other ; it will then at once be obvious to which lot - and therefore to which species - it rightly belongs.

As indicated above, eleven species of Raia are landed more or less. regularly at the various fishing ports of Devon and Cornwall. These are $R$. montagui, $R$. brachyura, $R$. undulata, $R$. microcellata, $R$. clavata, $R$. naevus, $R$. circularis, $R$. fullonica, $R$. marginata, $R$. batis, and $R$. oxyrhynchus. $\dagger$ These eleven species fall naturally into two main divisions :-

I. those whose under sides are of a decidedly dark ground-colour richly studded with black spots and which, for our present purpose, may be called "Black-bellied Species."

II. "White-bellied Species."

* For such detailed descriptions reference should be made to Clark's admirable monograph on the European species of Raia (1).

$\dagger$ Nomenclature according to Clark's monograph (1). 


\section{Black-Bellied Species (Skates).}

Only two species- $R$. batis Linn., and $R$. oxyrhynchus Linn.-are included in this division. They are separately distinguished as follows :--

\section{RAIA OXYRHYNCHUS.}

Long-nosed Skate.

Bottle-nosed Skate.

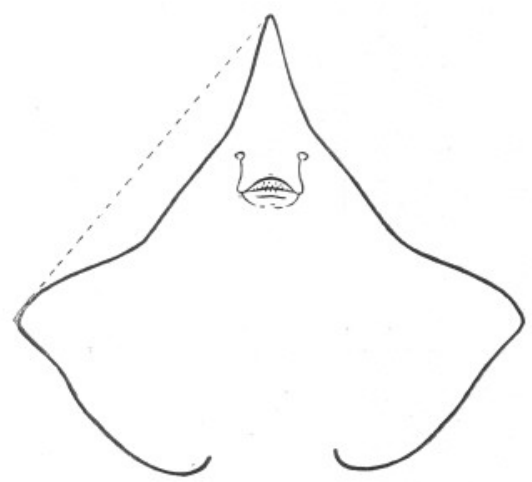

Fig. 1A.—Raia oxyrhynchus—outline of dise.
RAIA BATIS.

Common Skate.

Blue Skate.

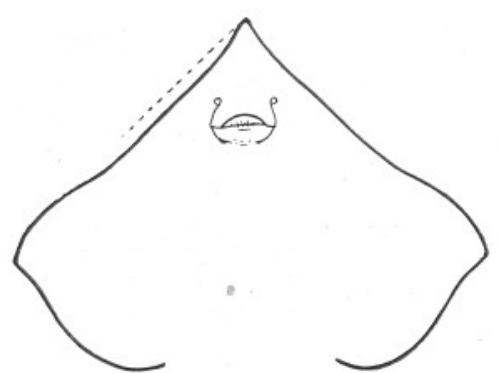

FIG, 1в.-Raia batis-outline of disc.

(Fig. 1в.)

Snout relatively much shorter, broader, and less pointed than in $R$. oxyrhynchus.

Outline of anterior margin of disc only slightly concave, often nearly straight.

Grows to a very large size, specimens of $150 \mathrm{~cm}$. in width being not uncommon.

Large Skates are generally picked out by the fishermen and spread separately on the fishmarket. The smaller sizes, up to about $50 \mathrm{~cm}$. across the disc, are laid out with the Rays interspersed indiscriminately among them. 


\section{White-bellied Species (Rays).}

These fall into three distinct groups, according to the shape of the disc.

1. LONG-NOSED RAYS . $\cdot\left\{\begin{array}{l}R \text {. fullonica Linnæus. } \\ R \text {. marginata Lacépède. }\end{array}\right.$

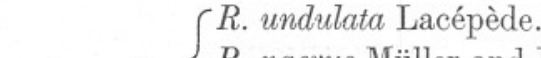

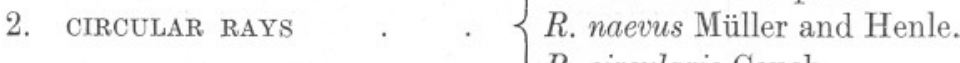

R. circularis Couch.

3. SHORT-NOSED RAYS. $\{R$. brachyura Lafont.

R. montagui Fowler.

R. inicrocellata Montagu.

\section{LONG-NOSED RAYS.}

The two species included in this group both have long and pointed snouts which mark them out at once from all the others.

RAIA FULLONICA.

Shagreen Ray.

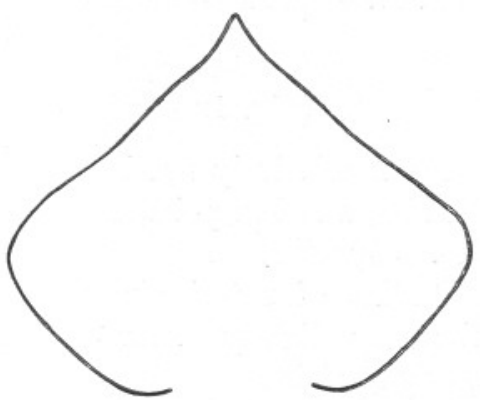

Fig. 2A.-Raia fullonica-outline of disc.

(Figs. 2A and 3.)

There is a well-marked groove (Fig. 3, G) in the middle of the upper jaw and a corresponding
RAIA MARGINATA.

Bordered Ray (Young). White-bellied Skate* (Adult).

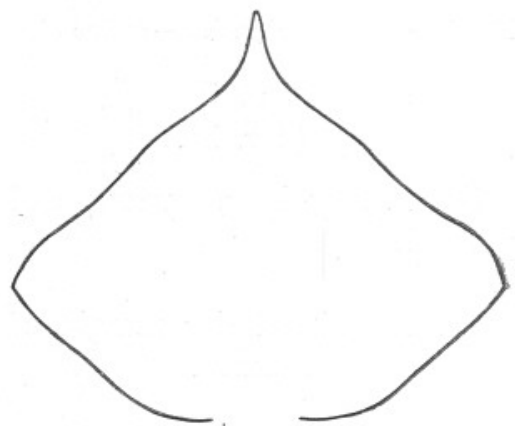

FIG. 2B.-Raia marginata-outline of disc.

(Figs. $2 \mathrm{~B}$ and 4.)

Curve of mouth cleft quite regular.

* The large adults of this species are known to fishermen as "White-bellied Skates" and are laid out apart from the Rays, either by themselves or along with the large Blue and Bottle-nosed Skates. They are then very conspicuous because of the clear whiteness. of their under sides, sharp snouts, and strongly undulated anterior disc margins. 


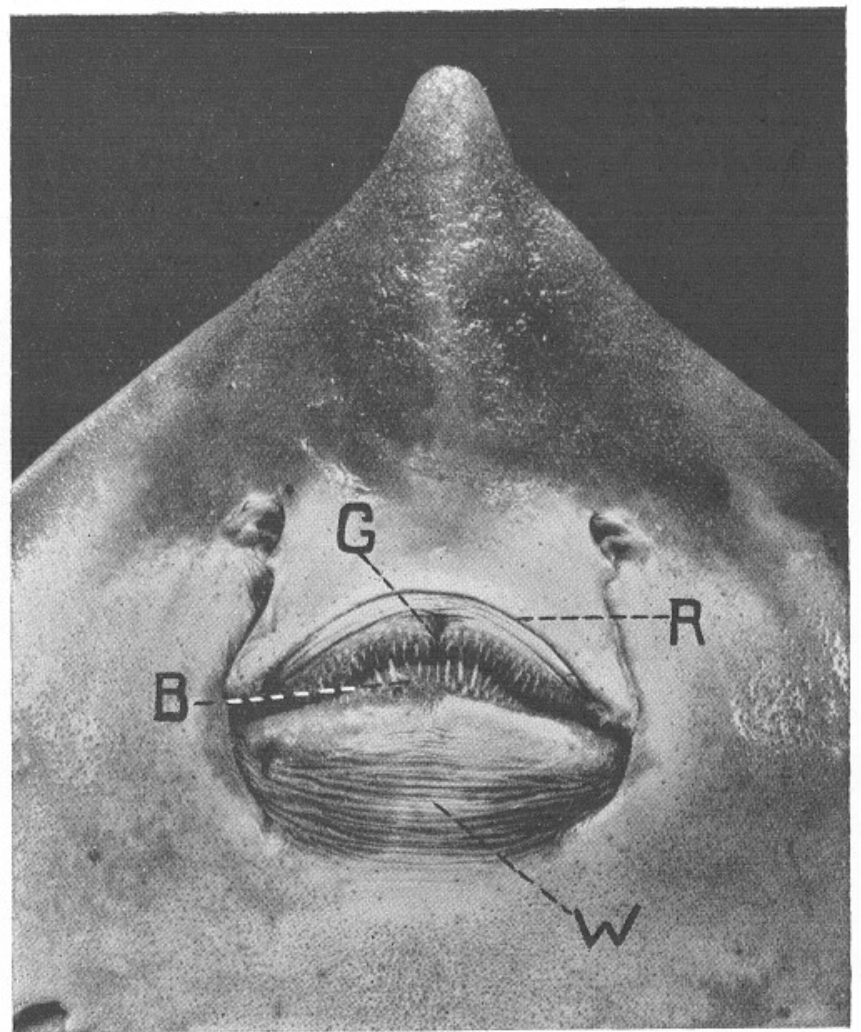

FIg. 3.-Raia fullonica-mouth and nasal regions. $\mathrm{R}$-pre-oral recess.

$\mathrm{G}$ - groove in middle of upper jaw.

B- "boss" in middle of lower jaw,

W-post-oral wrịnkled region,

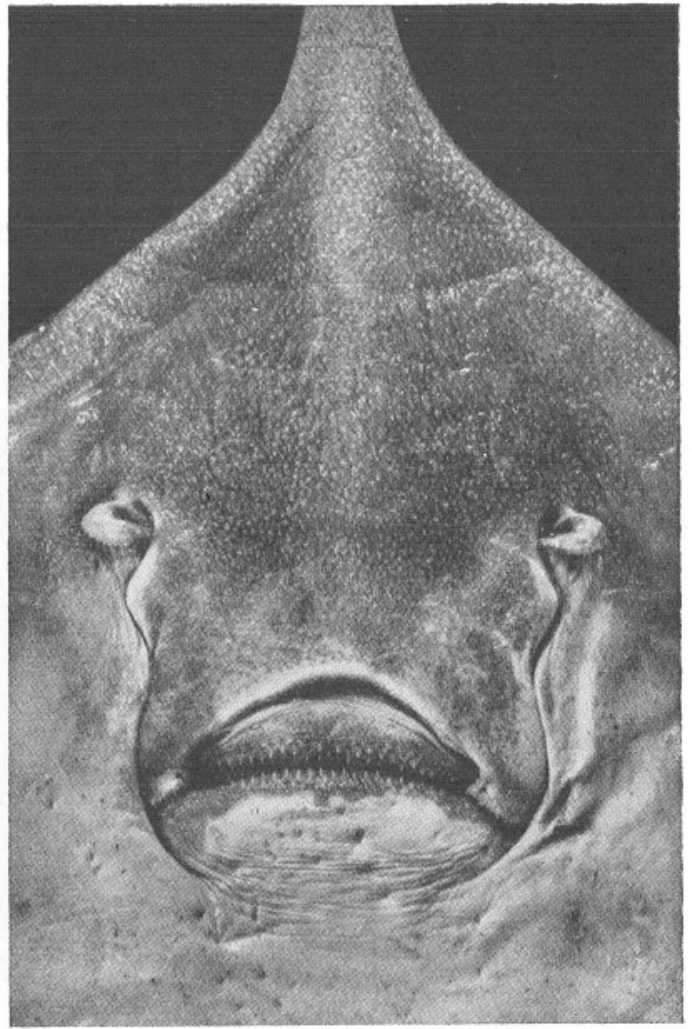

Fig, 4.-Raia marginata-mouth and nasal regions, 
"boss" (Fig. 3, B) in the middle of the lower jaw which give the mouth cleft a very irregular outline,

Internasal distance appreciably less than width of mouth.

Anterior margin of disc not strongly undulated.

Ventral surface of tail white.

Seldom grows beyond $70 \mathrm{~cm}$. in width of disc.
Internasal distance about equal to, or slightly greater than, width of mouth.

Anterior margin of disc strongly undulated.

Ventral surface of tail darkcoloured, sometimes nearly black.*

Adults very large, up to $150 \mathrm{~cm}$. across the disc.

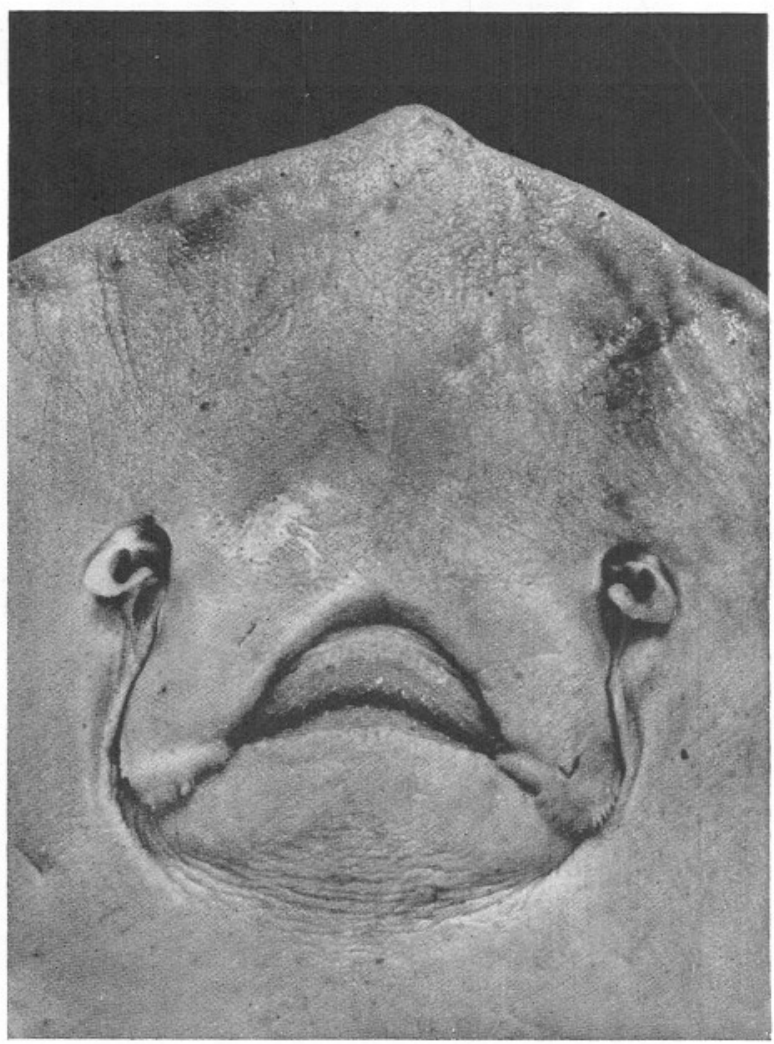

FIG. 5.-Raia undulata-mouth and nasal regions.

* In very young individuals there is a broad black band around the tips and along the posterior margins of the wings, but as this gradually disappears with age, it cannot be used with confidence for distinguishing the species. 


\section{CIRCULAR RAYS.}

The three species which fall into this group all have the tips of their wings decidedly rounded and their snouts scarcely project in front of the main contour of the disc-characters which give them a typically " circular" appearance.

\section{RAIA UNDULATA. \\ Marbled Ray.}

(Fig. 5).

Arch of pre-oral recess high and acute.

Teeth flattened and close set, so that the separate rows are not discernible.

"Groove and boss" absent.

RAIA NAEVUS.

Cuckoo Ray.

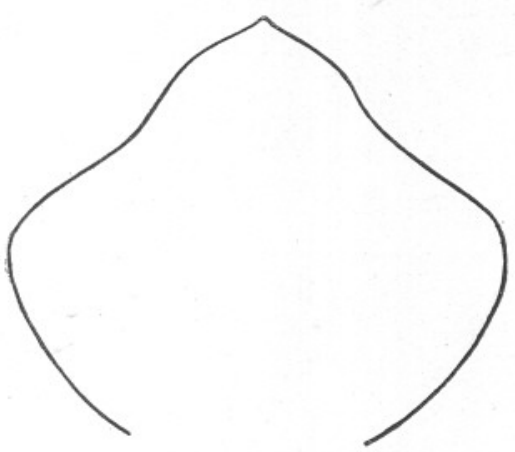

FIG. 6A.-Raia naevus-outline of disc.

(Fig. 6a.)
RAIA CIRCULARIS.

Sand Ray.

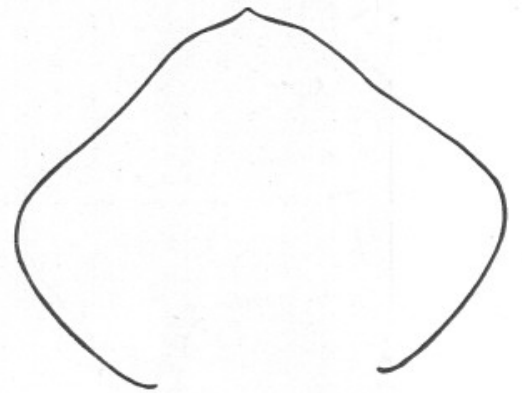

FIG. 6B.-Raia circularis-outline of disc.

(Fig. 6b.)

Arch of pre-oral recess low and obtuse.

Teeth long, pointed, and in widely separated rows which show up clearly.

"Groove and boss" generally discernible.

Anterior margin of disc Anterior margin of disc not strongly undulated.

Fish very thick and fleshy.

The smallest of the Devon and Cornwall Rays, seldom exceeding $40 \mathrm{~cm}$. across the disc. strongly undulated.

Fish always appreciably thinner than a specimen of $R$. naevus of the same width across the disc.

Adults commonly as much as $70-75 \mathrm{~cm}$. across the disc. 


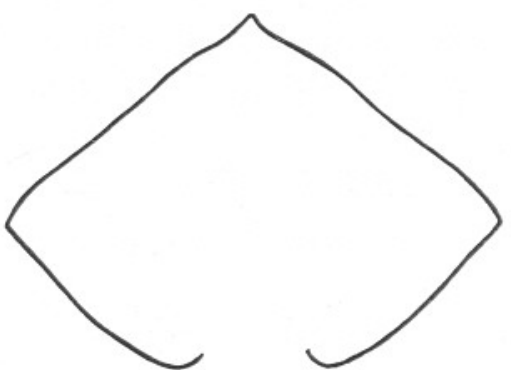

Fig. 7.-Raia clavata-outline of disc.

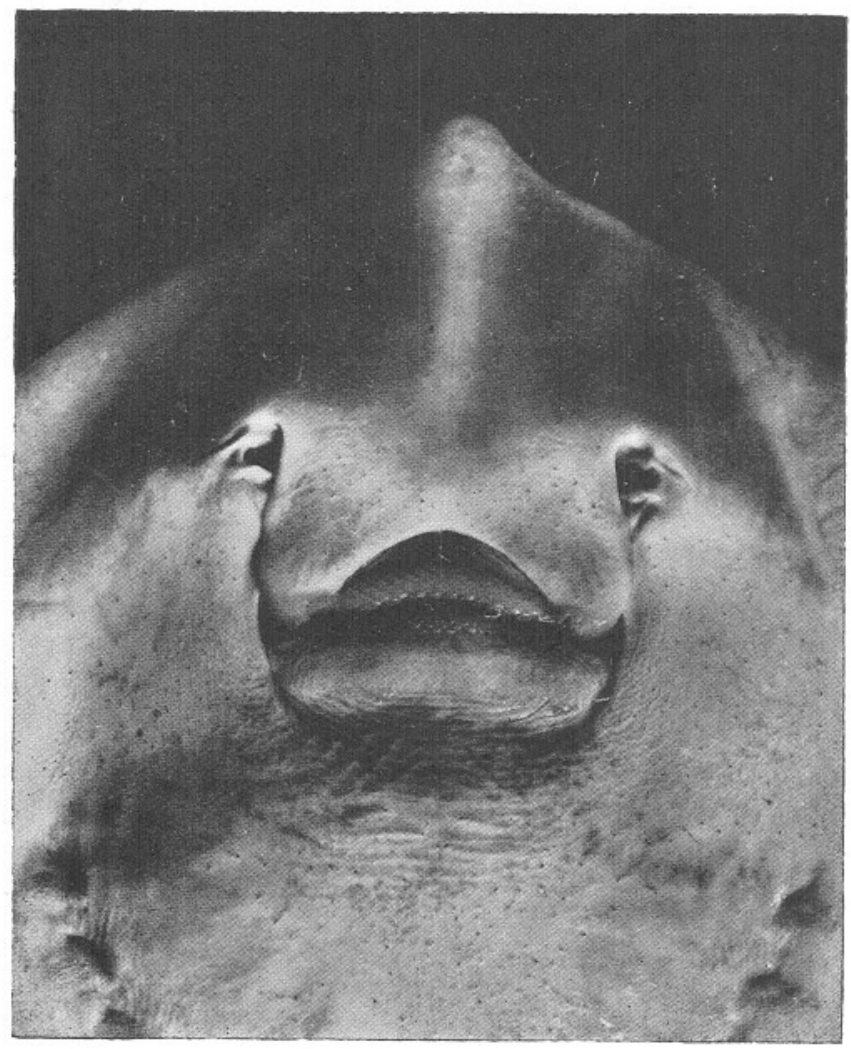

FIG. 8.-Raia clavata-mouth and nasal regions. 


\section{SHORT-NOSED RAYS.}

In each of the four species included in this group, the general outline of the disc is typically diamond-shaped, due to the sharpness of the wingtips and the presence of a short but well-defined snout (see Fig. 7).

\section{RAIA CLAVATA.}

Thornback Ray.

(Figs. 7 and 8.)

Arch of pre-oral recess high and acute.

Teeth large and distinct, markedly tessellated in adult females and in immature specimens of both sexes; more pointed in adult males.

Internasal width about equal to width of mouth.

Lower surface with large spines and/or rough patches.

\section{RAIA BRACHYURA.}

Blonde Ray.

(Fig. 9.)

\section{RAIA MONTAGUI.}

Spotted Ray. Homelyn Ray.

(Fig. 10.)

Arch of pre-oral recess low and obtuse (except in adult males).

Internasal distance always less than width of mouth.

Large spines never present on lower surface.

Outline described by oro-nasal canals and hinder margin of postoral wrinkled area (see Fig. 3, W) forming a wide $\{\rho$ with nearly straight or even concave base.

Surface smooth all over except in large adults which may show some rough patches.

Often grows to $80 \mathrm{~cm}$. in width of disc.
Outline described by oro-nasal canals and hinder margin of postoral wrinkled area forming a more rounded \& 9 with convex base.

Surface smooth at all ages.

Seldom grows beyond $50 \mathrm{~cm}$. across the disc. 


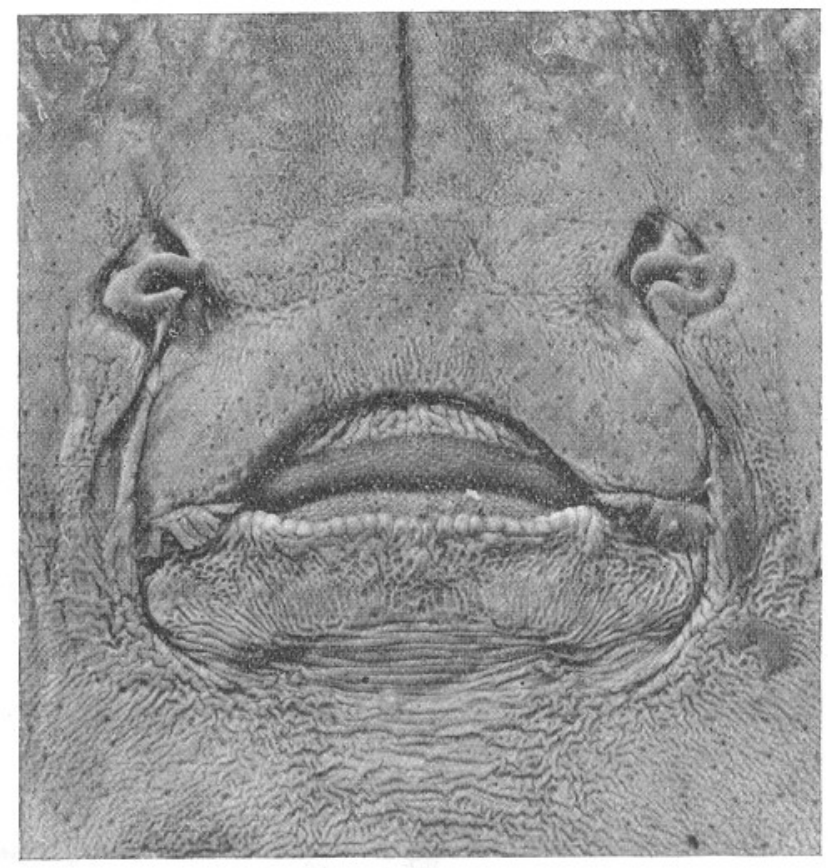

FIG. 9.-Raia brachyura-mouth and nasal regions.

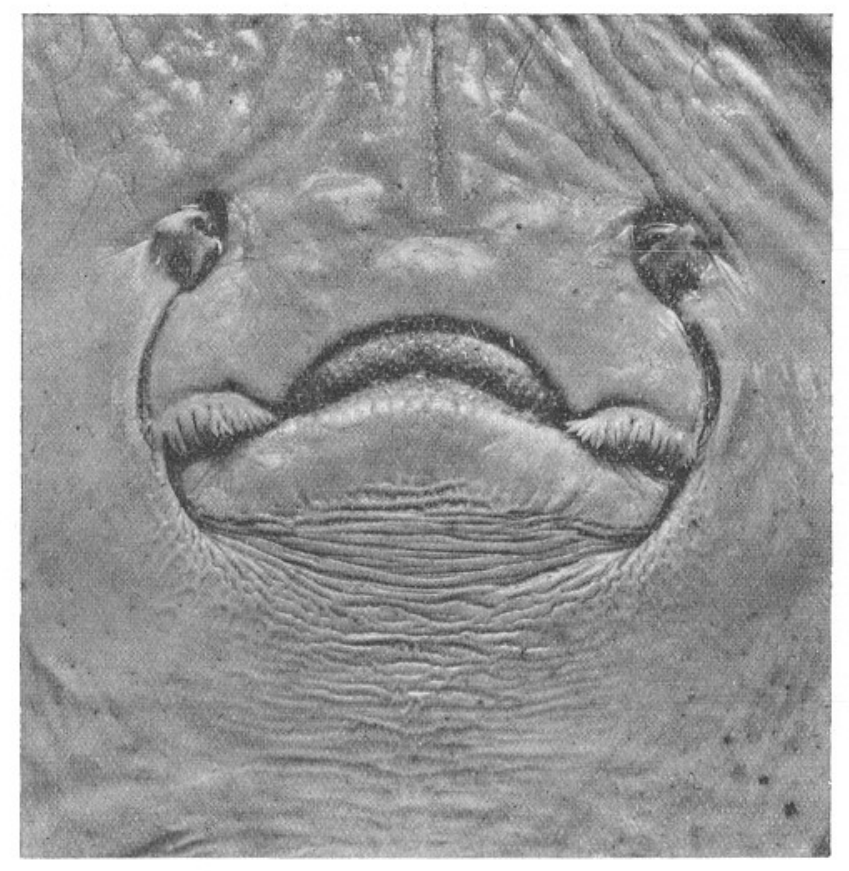

FIG. 10.-Raia montagui-mouth and nasal regions. 


\section{RAIA MICROCELLATA.}

Painted Ray.

Resembles $R$. montagui in the characters of the mouth and nasal regions, but the pre-nasal area is covered with small spinulæ. In large specimens these are easily seen, but in smaller individuals it sometimes is necessary to touch the surface with the fingers in order definitely to establish their presence or absence.

Adults often grow to $70 \mathrm{~cm}$. across the disc.

\section{BIBLIOGRAPHY.}

1. Clark, Robert S. Rays and Skates; a Revision of the European Species. Fisheries, Scotland, Sci. Invest. 1926, I. (1926).

2. Rey, Luis Lozano. Peces. Fauna Ibérica, Tomo Primero. Museo Nacional de Ciencias Naturales, Madrid, 1928. 
